\title{
PROFIL PENDERITA STROKE DENGAN HIPERTENSI DI BAGIAN RAWAT INAP NEUROLOGI RSUP PROF. DR. R. D. KANDOU MANADO PERIODE JULI 2013 - JUNI 2014
}

\author{
${ }^{1}$ Caroline G. Senaen \\ ${ }^{2}$ Mieke A. H. N Kembuan \\ ${ }^{2}$ Rizal Tumewah
}

\author{
${ }^{1}$ Kandidat Skripsi Fakultas Kedokteran Universits Sam Ratulangi Manado \\ ${ }^{2}$ Bagian Neurologi Fakultas Kedokteran Universits Sam Ratulangi Manado \\ Email: c.senaen_11_270@yahoo.co.id
}

\begin{abstract}
Stroke is a disease of acute neurological deficits caused by brain blood vessel disorder that occurs suddenly and causes symptoms and signs that correspond to the affected brain regions. High blood pressure, also known as hypertension, is one of the major risk factors of hemorrhagic stroke and ischemic stroke. Hypertension can lead to rupture or narrowing of blood vessels of the brain. This study aimed to identify the profile of stroke patients with hypertension in inpatients of Neurology Department Prof. Dr R. D. Kandou Hospital Manado from July 2013 to June 2014. This was a descriptive retrospective study. In this study, there were 162 patients with stroke who met the inclusion criteria. There were 74 male patients and 88 female patients. Most patients were 55-65 years, had high school education, and were housewives. Most systolic blood pressures were at grade 3 and diastolic hypertension at grade 2. Based on types of stroke, most patients had ischemic stroke.
\end{abstract}

Keywords: gender, age, education, occupation, blood pressure, type of stroke

\begin{abstract}
Abstrak: Stroke adalah suatu penyakit defisit neurologis akut yang disebabkan oleh gangguan pembuluh darah otak yang terjadi secara mendadak dan menimbulkan gejala dan tanda yang sesuai dengan daerah otak yang terganggu. Tekanan darah tinggi atau yang dikenal dengan hipertensi merupakan salah satu faktor resiko utama, baik untuk stroke hemoragik maupun stroke iskemik. Hipertensi dapat mengakibatkan pecahnya maupun penyempitan pembuluh darah otak. Penelitian ini bertujuan untuk mengetahui profil penderita stroke dengan hipertensi di Bagian Rawat Inap Neurologi RSUP Prof. Dr. R. D. Kandou Manado periode Juli 2013 Juni 2014. Penelitian ini menggunakan metode retrospektik deskriptif dengan 162 pasien stroke yang memenuhi kriteria inklusi. Pasien stroke berjenis kelamin laki - laki sebanyak 74 dan perempuan 88 orang. Sebagian besar pasien stroke berusia 55 - 65 tahun, pendidikan SMA dan pekerjaan terbanyak ialah ibu rumah tangga. Berdasarkan tekanan sistolik, sebagian besar dengan hipertensi derajat 3 sedangkan berdasarkan tekanan diastolik yaitu hipertensi derajat 2. Berdasarkan jenis stroke terbanyak ialah stroke iskemik.
\end{abstract}

Kata kunci: jenis kelamin, umur, pendidikan, pekerjaan, tekanan darah, jenis stroke

Stroke adalah suatu penyakit defisit neurologis akut yang disebabkan oleh gangguan pembuluh darah otak yang terjadi secara mendadak dan menimbulkan gejala dan tanda yang sesuai dengan daerah otak yang terganggu. ${ }^{1}$
Stroke atau yang dikenal dengan istilah gangguan peredaran saraf otak (GPDO) adalah suatu sindrom yang diakibatkan oleh adanya gangguan aliran darah pada salah satu bagian otak yang menimbulkan gangguan fungsional otak berupa defisit 
neurologis atau kelumpuhan saraf. ${ }^{2}$

Di Amerika Serikat, penyakit serebrovaskular (stroke) merupakan penyebab kematian tersering ketiga setelah penyakit jantung dan kanker. Angka kematian setiap tahun akibat stroke baru atau rekuren ialah lebih dari 200.000 orang. Insiden stroke secara nasional diperkirakan sekitar 750.000 per tahun dimana dua pertiga penderita stroke berusia lebih dari 65 tahun. ${ }^{3}$ Berdasarkan data Riset Kesehatan Dasar (Riskesdas) tahun 2007, menunjukan angka kematian sebesar 15,4\%, menjadikan stroke sebagai penyebab kematian tertinggi di Indonesia. ${ }^{4}$

Stroke dibagi menjadi 2, yaitu stroke hemoragik dan stroke non hemoragik (iskemik). Stroke hemoragik yang diakibatkan oleh pecahnya suatu mikroaneurisme di otak (perdarahan otak). Stroke hemoragik sendiri terbagi atas perdarahan intraserebral dan subaraknoid. Stroke non-hemoragik (iskemik) yang disebabkan oleh oklusi pembuluh darah otak, yang kemudian menyebabkan terhentinya pasokan oksigen dan glukosa diotak. $^{5}$

Tekanan darah tinggi atau yang dikenal dengan hipertensi merupakan salah satu faktor resiko utama, baik untuk stroke hemoragik maupun stroke iskemik. Hipertensi dapat mengakibatkan pecahnya maupun penyempitan pembuluh darah otak. Hipertensi adalah tekanan darah sistol $\geq 140$ mmHg dan diastol $\geq 90 \mathrm{mmHg}^{6}$. Pada individu berusia 40-70 tahun, setiap kenaikan tekanan sistol $20 \mathrm{mmHg}$ atau kenaikan diastol $10 \mathrm{mmHg}$ akan meningkatkan risiko stroke 2 kali lipat. ${ }^{8}$

\section{METODE PENELITIAN}

Penelitian ini menggunakan metode deskriptif retrospektif yaitu dengan mengambil data sekunder berupa data rekam medis. Populasi penelitian ialah pasien stroke di Bagian Rawat Inap Neurologi RSUP Prof. Dr. R. D. Kandou Manado dari bulan Juli 2013 - Juni 2014 yang berjumlah 162 orang. Variabel penelitian ialah jenis kelamin, umur, pendidikan, pekerjaan, tekanan darah dan jenis stroke.Pengolahan data menggunakan program komputer SPSS (Statistical Program for Social Science) versi 20 dan hasilnya akan di tampilkan dalam tabel distribusi frekuensi.

\section{HASIL DAN BAHASAN}

Berdasarkan data yang diperoleh didapatkan penderita stroke yang terbanyak ialah perempuan sebanyak 88 pasien (54,3\%), sedangkan pada laki - laki sebanyak 74 pasien (45,7\%) (Tabel 1). Hal ini sesuai dengan hasil penelitian Sherly F et al. tahun 2014 dimana angka kejadian stroke pada perempuan lebih tinggi dibandingkan laki - laki. ${ }^{8}$

Tabel 1. Distribusi penderita stroke berdasarkan jenis kelamin

\begin{tabular}{ccc}
\hline Jenis Kelamin & Jumlah & $\%$ \\
\hline Laki - laki & 74 & 45,7 \\
Perempuan & 88 & 54,3 \\
\hline Total & 162 & 100,0 \\
\hline
\end{tabular}

Berdasarkan Tabel 2 didapatkan bahwa penderita stroke yang terbanyak pada kelompok umur 56-65 tahun yaitu 47 pasien (29,0\%). Hal ini sesuai dengan hasil Cintya $\mathrm{AD}$ et al. tahun 2013 dengan angka kejadian tertinggi pada usia $>50$ tahun. $^{9}$

Tabel 2. Distribusi penderita stroke berdasarkan umur

\begin{tabular}{ccc}
\hline Umur (Tahun) & Jumlah & $\%$ \\
\hline $26-35$ & 2 & 1,2 \\
$36-45$ & 26 & 16 \\
$46-55$ & 46 & 28,4 \\
$56-65$ & 47 & 29,0 \\
$>65$ & 41 & 25,3 \\
\hline Total & 162 & 100 \\
\hline
\end{tabular}

Berdasarkan Tabel 3, penderita stroke yang terbanyak adalah pada kelompok pendidikan SLTA yaitu 104 pasien (64,2\%). Hal ini sesuai dengan hasil Yuliaji S tahun 2005 yaitu pasien berpendidikan SMA lebih banyak dibandingkan tingkat pendidikan lainnya. ${ }^{10}$

Berdasarkan Tabel 4, penderita stroke yang terbanyak dengan profesi sebagai ibu rumah tangga yaitu 60 pasien $(37,0 \%)$. Hal 
ini sesuai dengan hasil penelitian Muh. Basri et al. tahun 2014 yaitu sebagian besar pasien stroke memiliki pekerjaan sebagai ibu rumah tangga. ${ }^{11}$

Tabel 3. Distribusi penderita stroke berdasarkan pendidikan

\begin{tabular}{ccc}
\hline Pendidikan & Jumlah & $\%$ \\
\hline SD & 30 & 18,5 \\
SLTP & 18 & 11,1 \\
SLTA & 104 & 64,2 \\
PT & 10 & 6,2 \\
\hline Total & 162 & 100,0 \\
\hline
\end{tabular}

Tabel 4. Distribusi penderita stroke berdasarkan pekerjaan

\begin{tabular}{ccc}
\hline Pekerjaan & Jumlah & $(\%)$ \\
\hline Tidak bekerja & 4 & 2,5 \\
IRT & 60 & 37,0 \\
PNS & 22 & 13,6 \\
Pensiunan & 19 & 11,7 \\
Wiraswasta & 12 & 7,4 \\
Pegawai swasta & 31 & 19,1 \\
Pendeta & 2 & 1,2 \\
Petani & 12 & 7,4 \\
\hline Total & 162 & 100,0 \\
\hline
\end{tabular}

Berdasarkan Tabel 5, penderita stroke yang terbanyak berdasarkan tekanan sistolik ialah hipertensi derajat 3 yaitu 49 pasien $(30,2 \%)$

Tabel 5. Distribusi penderita stroke berdasarkan tekanan sistolik

\begin{tabular}{ccc}
\hline $\begin{array}{c}\text { Tekanan } \\
\text { sistolik }\end{array}$ & Jumlah & $\%$ \\
\hline $\begin{array}{c}\text { Normal } \\
\text { Hipertensi } \\
\text { derajat } 1\end{array}$ & 36 & 22,2 \\
$\begin{array}{c}\text { Hipertensi } \\
\text { derajat 2 }\end{array}$ & 37 & 22,8 \\
$\begin{array}{c}\text { Hipertensi } \\
\text { derajat 3 }\end{array}$ & 49 & 30,2 \\
\hline Total & 162 & 100,0 \\
\hline
\end{tabular}

Berdasarkan Tabel 6, penderita stroke yang terbanyak berdasarkan tekanan diastolik ialah hipertensi derajat 2 yaitu 52 pasien $(32,1 \%)$.
Tabel 6. Distribusi penderita stroke berdasarkan tekanan diastolik

\begin{tabular}{ccc}
\hline $\begin{array}{c}\text { Tekanan } \\
\text { diastolik }\end{array}$ & Jumlah & $\%$ \\
\hline $\begin{array}{c}\text { Normal } \\
\text { Hipertensi } \\
\text { derajat } 1\end{array}$ & 51 & 31,5 \\
$\begin{array}{c}\text { Hipertensi } \\
\text { derajat } 2\end{array}$ & 52 & 32,1 \\
$\begin{array}{c}\text { Hipertensi } \\
\text { derajat 3 }\end{array}$ & 23 & 14,2 \\
\hline Total & 162 & 100,0 \\
\hline
\end{tabular}

Berdasarkan hasil pengumpulan data mengenai distribusi penyakit stroke yang di rawat inap di BLU Prof. Dr. R. D. Kandou Manado periode Juli 2013 - Juni 2014 didapatkan bahwa pasien stroke dengan hipertensi lebih banyak. Hal ini sesuai dengan hasil Cintya AD et al. tahun 2013 yaitu pasien stroke dengan jumlah terbanyak mempunyai faktor risiko hipertensi. ${ }^{9}$

Tabel 7 menunjukkan penderita stroke terbanyak dengan jenis stroke iskemik yaitu 88 pasien (54,3\%). Hal ini sesuai dengan hasil penelitian Mochammad B tahun 2009 yaitu stroke iskemik lebih banyak ditemukan dibandingkan stroke hemoragik. $^{12}$

Tabel 7. Distribusi penderita stroke berdasarkan jenis stroke

\begin{tabular}{ccc}
\hline Jenis stroke & Jumlah & $\%$ \\
\hline $\begin{array}{c}\text { Stroke } \\
\text { iskemik } \\
\begin{array}{c}\text { Stroke } \\
\text { hemoragik }\end{array}\end{array}$ & 88 & 54,3 \\
\hline Total & 162 & 45,7 \\
\hline
\end{tabular}

\section{SIMPULAN}

Berdasarkan hasil penelitian tentang profil stroke dengan hipertensi di Bagian Rawat Inap Neurologi RSUP Prof. Dr. R. D. Kandou Manado periode Juli 2013 - Juni 2014, dapat disimpulkan bahwa:

1. Pasien stroke terbanyak ialah perempuan, kelompok umur 56-65 tahun, berpendidikan SMA, dengan pekerjaan ibu rumah tangga. 
2. Berdasarkan tekanan darah saat masuk rumah sakit, didapatkan tekanan sistolik terbanyak $\geq 140 \mathrm{mmHg}$ dan tekanan diastolik $\geq 90 \mathrm{mmHg}$.

3. Jenis stroke terbanyak ialah stroke iskemik.

\section{SARAN}

1. Perlu adanya penyimpanan data rekam medik yang lebih baik agar status pasien dapat disimpan dengan baik dan menghindari hilangnya status pasien.

2. Bagi tenaga medis agar melengkapi catatan rekan medik pasien agar dapat diperoleh data yang lebih akurat untuk digunakan dalam penelitian.

3. Diperlukan penyuluhan kepada masyarakat mengenai factor - factor resiko dari stroke agar angka kejadian stroke dapat dihindari.

4. Diharapkan adanya penelitian lebih lanjutan dengan menggunakan metode penelitian yang lebih baik.

\section{DAFTAR PUSTAKA}

1. Bustan MN. Stroke. Dalam : Rineka Cipta, editor. Epidemiologi penyakit tidak menular. Edisi ke-2. Jakarta: Rineka Cipta; 2007.h.79-80.

2. Gustaviani R. Diagnosis dan klasifikasi diabetes mellitus. Dalam: Aru SW, S Bambang, A Idrus, KM Simadibrata, Setiada S, editor. Buku Ajar Ilmu Penyakit Dalam. Edisi ke-4. Jakarta: Pusat Departemen Ilmu Penyakit Dalam Fakultas Kedokteran Universitas Indonesia; 2007: p.1857-9.

3. Price SA, Wilson LM. Patofisiologi :konsep klinis proses -proses penyakit. Edisi ke-6. Jakarta: EGC; 2005.h.1106
4. Sebastian E, Kustiowati E, Noorwijayahadi. Asosiasi genotip apolipoprotein E dengan keluaran pasien pasca stroke iskemik. Med Hosp.2013;1:169.

5. Martono H, Kuswardini T. Stroke dan penalaksanaan oleh internis: an overview. Dalam: Sudoyo W Aru, dkk, editor. Buku ajar ilmu penyakit dalam. Edisi ke-4. Jakarta: University; 2006.h.1411

6. Harsono (editor). Buku ajar neurologi klinis. Edisi ke-1. Yogyakarta: GM University; 1996; p. 61-9.

7. JNC 7 Express. The seventh report of the joint national committee on prevention, detection, evalution, and treatment of high blood pressure: NIH Publication; 2003.

8. Fandri S, Utomo W, Dewi PA. Perbedaan status fungsional pasien stroke saat masuk dan keluar ruang rawat inap RSUD Arifin Achmad. JOM PSIK. 2014;1:2.

9. Dinata CA, Safira Y, Sastria S. Gambaran factor risiko dan tipe stroke pada pasien rawat inap di bagian penyakit dalam RSUD Kabupaten Solok Selatan periode 1 januari 2010 - 31 juni 2013. Kesehatan Andalas. 2013.

10.Siswanto $Y$. Beberapa factor risiko yang mempengaruhi kajadian stroke berulang [Tesis]. Semarang: Universitas Diponegoro, 2004.

11.Basri M, Yusdar. Hubungan golongan darah dengan prevalensi stroke di rumah sakit khusus daerah provinsi Sulawesi Utara. Kesehatan diagnosis. 2014;4:642.

12.Bahrudin M. Model diagnostik stroke berdasarkan gejala klinis. Malang:Staf pengajar pada Fakultas Kedokteran, 2009. 